\title{
6
}

\section{LITERATURA E INDÚSTRIA CULTURAL: UM ESTUDO SOBRE ROMANCE-FOLHETIM COMO CULTURA DE MASSA}

\section{LITERATURE AND CULTURAL INDUSTRY: A STUDY ON ROMANCE-SERIAL AS MASS CULTURE}

\author{
Naiara Sales Araújo ${ }^{1}$ \\ Universidade Federal do Maranhão \\ Isadora Fernandes Figueiredo ${ }^{2}$ \\ Universidade Federal do Maranhão
}

Resumo: O presente artigo tem por objetivo refletir sobre a atuação da indústria cultural nas artes, primordialmente no romance-folhetim, por intermédio dos meios de comunicação. A partir dos estudos dos filósofos e sociólogos alemães Theodor Adorno (1903-1969) e Max Horkheimer (18951973), no que diz respeito a indústria cultural e cultura de massa, identificar-se-á como a literatura, mediante romances-folhetins, pôde tornar-se parte congruente da cultura de massa. Os resultados sugerem que a indústria cultural se tornou um dos principais veículos de produção no que se refere à arte no capitalismo moderno.

Palavras-Chave: Indústria Cultural; Cultura de Massa e Ideologia; Literatura; Romance-folhetim.

\footnotetext{
Endereço eletrônico: naiara.sas@ufma.br.

2 Endereço eletrônico: isadoraffigueiredo@hotmail.com.
} 
Abstract: This article aims to reflect on the role of the cultural industry in the arts, primarily in the novelserial, through the media. To do so, we build on the literary scholarship of the German philosophers and sociologists Theodor Adorno (1903-1969) and Max Horkheimer (1895-1973), with regard to the cultural industry and mass culture. Thus, we will provide a discussion on how Literature, through Romance-serials, could become a congruent part of mass culture. The results suggest that the cultural industry has become one of the most important vehicles of production when it comes to art in modern capitalism.

Keywords: Cultural Industry; Mass Culture and Ideology; Literature; Romance-serial.

\section{INTRODUÇÃO}

Os estudos realizados por Max Horkheimer (1895-1973) e Theodor Adorno (1903-1969), membros da Escola de Frankfurt, foram utilizados primeiramente no texto Indústria Cultural: o esclarecimento como mistificação das massas (1944) e definiram o que hoje se entende por indústria cultural e cultura de massa.

O estudo proposto pela escola de Frankfurt pontua que a partir do capitalismo industrial houve uma abertura para a indústria cultural, principalmente devido à produção em massa de produtos e sua necessidade de venda. Dessa forma, a cultura de massa busca contentar o maior número de grupos e apresenta-se como produto da indústria cultural, que concentra suas demandas nas massas populares, independentemente de faixa etária, gênero, orientação sexual e classe econômica.

Na visão de Adorno (1944), para que a indústria alcance essa massa, cada setor de produção é uniformizado em relação aos outros, conferindo à civilização semelhança e homogeneidade. Dessa maneira, os meios de comunicação se tornam as principais ferramentas de manipulação e popularização do produto, haja vista o cultivo de uma cultura de consumo, que requer um apelo visual e persuasivo. Assim, o que atrai pessoas para consumir certos produtos é o "escape" que eles propõem, causando uma impressão de alacridade, contentamento que, de acordo com Horkheimer e Adorno (1944), estimulam, nas 
pessoas, um esquecimento e um apaziguamento das tendências capitalistas que assolam a sociedade.

O uso da arte como produto de lucro pode ser visto desde o século XIX, a partir do crescimento dos meios de comunicação, primordialmente do jornal e sua produção em massa, o qual se utilizou da literatura para aumentar suas vendas. A literatura, então, mais especificamente os romances, começa a ser publicada no rodapé dos jornais, e depois em espaços maiores, em razão do interesse do público que queria consumi-la. Assim, a literatura, por meio do romance-folhetim, tornou-se um produto cultural para acúmulo de capital.

A partir da comercialização dos romances-folhetins publicados nesses jornais, inicia-se o processo de inserção da literatura no que mais tarde seria a chamada "cultura de massa", visto que o romance-folhetim, por meio de uma fidelidade à opinião do leitor, deixava claro sua legitimidade como mercadoria da indústria cultural, propagando-se por meio da comunicação em massa dos jornais e de uma economia mercadológica.

Dessa maneira, o gênero começou a ser visto como uma literatura subjugada pelas regras da indústria, visto que seu conteúdo, sua forma e seu estilo estavam sujeitos a uma adequação que dependia da opinião e, consequentemente, do acompanhamento do maior número de leitores. À vista disso, este artigo busca refletir como a literatura se estabeleceu como produto da indústria cultural, tornando-se parte congruente da cultura de massa.

\section{A INDÚSTRIA CULTURAL: OBTENÇÃO DE LUCRO E CONSUMO EXCESSIVO DAS MASSAS}

A definição de indústria cultural - apresentada primariamente por Max Horkheimer (1895-1973) e Theodor Adorno (1903-1969) - é constituída a partir de críticas correlacionadas à produção massiva e de cunho capitalista em relação à arte. 
Horkheimer e Adorno, vale ressaltar, são os principais representantes da primeira geração do grupo formado na Alemanha, em meio à Segunda Guerra Mundial, conhecido como Escola de Frankfurt (Frankfurter Schule), nome utilizado primeiramente no texto intitulado Indústria Cultural: o esclarecimento como mistificação das massas, o qual foi, posteriormente, inserido como capítulo da obra Dialética do Esclarecimento (Dialektik der Aufklärung), publicada em 1947 (PUTERMAN, 1994).

A escola de Frankfurt, instituída com pensamento filosófico e sociológico, nasceu a partir de um projeto de intelectuais vinculados à Universidade de Frankfurt. Um dos seus principais estudos intercorreu à reflexão do que seria a indústria cultural, sobretudo no que tangia à produção e distribuiç̧ão em série de itens artísticos, transformados em produtos culturais (JACKS, 1998, p. 25).

Horkheimer e Adorno (1944), assim como outros pensadores, a exemplo de Friedrich Pollock (1894-1970), Felix Weil (1898-1975) e Erich Fromm (19001980), fundamentaram seus estudos nos conceitos marxistas, na psicanálise e também na sociologia antipositivista, sendo todos pertencentes à primeira geração dessa escola, que perduraria por mais tempo.

Em seus estudos, promoviam embates entre cultura e ciência, com o intuito de buscar alternativas para a reestruturação de uma sociedade, haja vista que, segundo essa escola, o homem, antes, era aprisionado por seus instintos e agora estava aprisionado por uma "falsa razão".

Com o abandono do pensamento - que em sua figura coisificada como matemática, máquina, a organização se vinga dos homens dele esquecidos o esclarecimento abdicou de sua própria realização. Ao disciplinar tudo que é único e individual, ele permitiu que o todo não compreendido se voltasse, enquanto dominação das coisas, contra o ser e a consciência dos homens. (ADORNO; HORKHEIMER, 1985, p. 51)

Essa dominação, segundo a escola de Frankfurt, se deu devido às consequências deixadas pela Revolução Industrial, em razão do acúmulo de 
capital, pois, por efeito da grande produção, era necessária uma grande venda, ou seja, muitas pessoas precisavam comprar. Nessa visão, Cardoso (2005) afirma:

A sociedade manufatureira surge, no século XIX, com a mecanização imposta pela Revolução Industrial; mediante a ampliação extraordinária da capacidade produtiva, de um deslocamento de ênfase para o processo de produção em si, para a produção "sem começo e sem fim" de bens de consumo de reduzida durabilidade, não mais focada na durabilidade, não mais focada na utilidade do produto. (CARDOSO, 2005, p. 86)

Assim, para que houvesse grande distribuição, deu-se início a uma propaganda ideológica de consumismo. Uma ideologia em que a individualidade era esquecida. Os frankfurtianos perceberam que esse pensamento influenciava a realidade da sociedade por meio de uma padronização, ou seja, um conjunto de ideias massificadoras que são naturalizadas pelas classes dominadas, uma falsa consciência sistematizada da realidade. "A cultura da mídia promove espetáculos cada vez mais sofisticados para conquistar audiências e aumentar o poder e o lucro da indústria cultural" (KELLNER, 2006, p.119).

Isso se sucede por meio da ocorrência de um padrão de formas culturais, visando não a estética, mas sim o lucro, o qual é assegurado em uma produção social do gosto, não exclusiva, e pluriclassista.

A unidade evidente do macrocosmo e do microcosmo demonstra para os homens o modelo de sua cultura: a falsa identidade do universal e do particular. Sob o poder do monopólio, toda cultura de massas é idêntica, e seu esqueleto, a ossatura conceitual fabricada por aquele, começa a se delinear. (ADORNO; HORKHEIMER, 1944, p. 114)

Dessa forma, a ideologia do consumismo deve ser vista como um pensamento aliado ao capitalismo, e que possui força na classe dominante, uma vez que é a responsável por deter os meios de produção e distribuí-los em massa, 
com a finalidade de manter certo padrão nas relações entre os consumidores e os objetos de consumo.

A homogeneidade do gosto, por seu lado, favorece o funcionamento da cultura em padrão de indústria, proporcionando uma massificação cultural. Assim, "a cultura contemporânea confere a tudo um ar de semelhança. O cinema, o rádio e as revistas constituem um sistema. Cada setor é coerente em si mesmo e todos o são em conjunto" (ADORNO; HORKHEIMER, 1944, p. 99). Assim, não há espaço para a subjetividade e valores individualizados.

Para assegurar essa homogeneidade, essa indústria se utiliza dos meios de comunicação, como jornais e revistas, bem como rádio, cinema e televisão, os quais estabelecem um conjunto fortificado de entretenimento que, consequentemente, gera lucro, produzindo uma cultura para consumo por meio de músicas, livros, programas televisivos, entre outros.

A partir desse sistema, em que há uma semelhança na compactação de conteúdo, tem-se uma diminuição em reflexão sobre o objeto e toda a produção técnica contribui para isso. Um exemplo é a televisão, enquanto síntese do rádio e do cinema.

Na cultura da imagem pós-moderna, estilo e aparência tornam-se parâmetros cada vez mais importantes de identidade e apresentação de si mesmo no cotidiano, e os espetáculos midiáticos mostram e dizem às pessoas como elas devem aparecer e se comportar. (KELLNER, 2006, p. 131-132)

Os meios de comunicação, por meio do seu alcance, influenciam a compra do produto, mostrando o que deve ser lido, assistido ou comprado e por meio disso ganham um retorno financeiro da lucratividade obtida pela marca patrocinadora.

Adorno e Horkheimer (1944) afirmam que o objeto artístico se torna publicidade, ocasionado pela fragilidade dos sistemas artísticos e culturais, posto que quando a obra é produzida para consumo, e presa à difusão, ela, assim, 
contribui e serve como influência à padronização de uma sociedade por completo.

\subsection{Cultura de massa: produto da indústria cultural}

Como dito anteriormente, a Indústria faz da cultura uma massificação. Assim, pode-se dizer que a cultura de massa se define como um sistema de formas de artes e conhecimentos que se apresentam de maneira pluriclassista requerida pela Indústria -, ou seja, com a função de servir a todas as classes sociais, e subordinada a ela, visando condições favoráveis para efetivação de seu comércio.

Desse modo, a produção de bens de consumo concentra suas demandas nas massas populares, independentemente de faixa etária, gênero, orientação sexual ou classe econômica, pois busca contentar todos os grupos. Na visão de Adorno (1985), cada setor de produção é uniformizado em relação aos outros, conferindo à civilização uma similitude.

Nesse sentido, a cultura de massa, por vezes, pode estar ligada a uma arte produzida por técnica e, segundo Walter Benjamin (1935), sem grande autenticidade e em larga escala para entreter o público. Um público que, antes, já foi preparado para recebê-la, por meio de uma propaganda ideológica realizada pelos meios de comunicação. Segundo o psicólogo e crítico da educação e industrialização, Antônio Álvaro Soares Zuin,

A ideologia encontra-se tão "colada" à realidade que qualquer comportamento que não se atrele ao atendimento das necessidades de consumo é rotulado como desviante. Não obstante, tem-se a impressão de que não há qualquer tipo de padronização ou uniformização do produto. Parece que vivenciamos uma identidade "única", já que nos diferenciamos de todos os outros que não usam nossas marcas socializadoras, tais como as marcas dos tênis e grifes de roupas famosas. (ZUIN, 2001, p. 12) 
Assim, na sociedade industrial, a cultura se transforma em mercadoria. E quanto mais vendida, mais padroniza a sociedade como um todo. "A arte renega a sua própria autonomia, incluindo-se orgulhosamente entre os bens de consumo..." (ADORNO; HORKHEIMER, 1985, p. 147).

Como produto da Indústria de Consumo, a cultura de massa é a junção de elementos de um conhecimento erudito, segundo Adorno, bem elaborado, junto a elementos de uma cultura popular, originada e produzida, anteriormente, apenas por determinado povo. Assim, esse conjunto resultaria em uma arte que pode ser produzida em proporção industrial.

É importante salientar que a cultura de massa difere da cultura popular, pois esta, geralmente, é própria de uma região - e legítima em sua origem -, ao passo que aquela continuamente procura um padrão, adaptando-se também aos mais diversos gostos.

Sob o poder do monopólio, toda cultura de massas é idêntica, e seu esqueleto, a ossatura conceitual fabricada por aquele, começa a se delinear. Os dirigentes não estão mais sequer muito interessados em encobri-lo, seu poder se fortalece quanto mais brutalmente ele se confessa de público. $\mathrm{O}$ cinema e o rádio não precisam mais se apresentar como arte. [...] Eles se definem a si mesmos como indústrias, e as cifras publicadas dos rendimentos de seus diretores gerais suprimem toda dúvida quanto à necessidade social de seus produtos. (ADORNO, 1985, p. 114)

Desse modo, a arte não é mais um espaço de apreciação, e sim de lazer, o que propende, segundo Adorno (1985), a uma diminuição de qualidade no seu conteúdo e na sua estética, dado que seu objetivo é mercantil. É uma produção cultural e comercial ao mesmo tempo, que não contém forte subjetividade, mas que possui um público que a consome. Sobre essa discussão, Edgar Morin, sociólogo e pesquisador francês que propõe ideias sobre organização do saber no pensamento contemporâneo, comenta: 
A cultura de massa é média em sua inspiração e seu objetivo, porque ela é a cultura do denominador comum entre as idades, os sexos, as classes, os povos, porque ela está ligada a seu meio natural de formação, a sociedade na qual se desenvolve sua humanidade média, de níveis de vida médios, de tipo de vida médio. (MORIN, 1997, p. 13)

O mercado, por meio da cultura de massa, oferece a diversão. Assim sendo, a cultura deixa de ser um aspecto de identidade e torna-se um entretenimento. O cinema, a exemplo, não é mais apenas um acúmulo do capital cultural; é também uma fuga de uma semana sobrecarregada de serviço, a qual a sociedade vai procurar para receber alívio. Ela "faz com que as massas consumam os produtos dessa indústria e, por conseguinte, esqueçam a realidade alienada que vivenciam" (FREITAG, 2004, p. 72).

Destarte, a cultura de massa se difere da cultura vista como expressão de valores, características e gostos de determinado povo, passando a ser designada como um produto industrial, criado para agradar uma massa e garantir seu objetivo primordial: o lucro.

\section{LITERATURA E INDÚSTRIA CULTURAL: O CASO DOS ROMANCES-FOLHETINS}

É possível compreender que o início da literatura como produto cultural se deu em 1836, com Émile de Girardin, escritor e jornalista francês e fundador do La presse, um jornal que introduziu a prática da publicidade na França e, posteriormente, no mundo. E foi por meio desse jornal que houve a publicação do primeiro folhetim, a novela picaresca espanhola, intitulada Lazarillo de Tormes (1836), de autoria desconhecida, sendo a primeira publicação de uma abundante quantidade que viria.

Seguindo a mesma ideia e interesse, inspirados por Girardin, outros jornais, para que garantissem maior circulação, ao perceberem como os 
romances-folhetins contribuíam para a venda do jornal, começaram a contratar equipes de autores, as quais escreviam romances com o intuito de agradar uma maioria de gostos, transformando-os, então, em um produto cultural.

Adorno (1985) afirma que as mudanças e evoluções na sociedade não podem ser vistas apenas pelos estudos das ideologias políticas, visto que, em sua maioria, se dão pela influência dos grandes meios de comunicação. E foi assim com a literatura, pois, por meio da abertura em massa dos jornais, esta sofreu uma nova adaptação, podendo ser utilizada como produto cultural para que houvesse acúmulo de capital.

Bourdieu (2013), por sua vez, valida a ideia de que o folhetim é um produto da indústria cultural, por meio de uma declaração realizada por um autor de folhetins da época, o qual escrevera mais de 15 obras.

Um bom exemplo do que estamos falando é a seguinte declaração de um escritor de roteiros de folhetins, autor de uns vinte romances, consagrados pelo prêmio Interallié e pelo Grande Prêmio da Academia francesa na categoria romance: "Minha única ambição é a de ser lido com facilidade pelo maior público possível. Eu nunca almejo a 'obra-prima' e não escrevo para intelectuais. Deixo esta tarefa para outros. "Para mim, um bom livro é aquele que nos cativa ao fim de três páginas". (BOURDIEU, 2013, p. 137)

Isso ratifica a concepção da literatura como cultura de massa, visto que, ao produzir a partir do gosto majoritário do leitor, o escritor produz suas obras para entretenimento, o que, ocasionalmente, segundo Adorno (1988), tende a diminuir a qualidade artística da obra.

Dessa maneira, mesmo que a literatura, em sua essência, tenha uma expressão de livre invenção na sua criação artística, ao ser transformada em produto da indústria cultural, favorece a produção das estéticas médias. (MORIN, 1997, p. 13). Assim, pode-se afirmar que essa mudança na literatura se deu a partir do momento em que começou a ser comercializada pelos meios de comunicação como objeto de venda. 
Essa literatura que nasce como cultura de massa diverge em vários objetivos daquela que não possui propósito lucrativo. “Qualidade à quantidade, criação à produção, espiritualidade ao materialismo, estética à mercadoria, elegância à grosseria, saber à ignorância (MORIN, 1997, p. 18). Nessa perspectiva, partindo da ideia de literatura como um produto da indústria cultural, o escritor passa a ser um operário apto a reproduzir em escala seu produto sem, contudo, ter autonomia total sobre o conteúdo e a forma de sua obra.

O folhetim, por meio da fidelidade à opinião do leitor, deixava claro sua legitimidade como mercadoria da indústria cultural, propagando-se por meio da comunicação em massa dos jornais e de uma economia mercadológica. Essa fidelidade ia ao encontro do gosto dos leitores e, em consequência disso, sua constante contribuição para os jornais fez com que o folhetim tivesse cada vez mais espaço, atribuindo benefício também aos autores.

Marlyse Meyer (1996) afirma que provavelmente todos os romances da época passaram a ser publicados nos jornais ou revistas na forma de periódicos antes de publicações em volume, por conta do sucesso obtido na primeira tiragem em folhetim. Isso fez com que eles construíssem um novo modelo de expressão e influência literária, já que em função de sua popularidade era o único modo de chegar ao público.

Outro aspecto relevante e que merece destaque é que, devido à influência da indústria cultural na estrutura do romance-folhetim, havia diferenças entre os elementos da linguagem utilizados pelo romance-folhetim e o romance publicado integralmente. Enquanto o último tinha como principal foco o emissor, o romance-folhetim dá enfoque ao receptor, pois ao ser publicado de capítulo em capítulo pode ou não sofrer alterações em sua história, conforme a receptividade de seus leitores.

Ademais, o modelo do romance-folhetim possuía uma tipologia textual que contemplava mais diálogos e comumente tinha como protagonista a figura 
de um herói que se movia em um mundo de extrema tensão social. Também eram frequentes nesses escritos contrastes de maniqueísmos, ou seja, bem versus mal, felicidade versus decepção, baixa sociedade versus alta sociedade.

Contudo, mesmo que fosse postulado como uma literatura menor, visto que sua finalidade era servir os assinantes - público em massa dos jornais da época -, sua popularidade só aumentava, um fato que chamou a atenção de autores já consagrados da época.

Muitas obras conhecidas como clássicos universais foram, primeiramente, publicadas em folhetins. Exemplos disso são: O Conde de Monte Cristo (1844) e Os Três Mosqueteiros (1844), de Alexandre Dumas; Madame Bovary (1856), de Gustave Flaubert; Os Miseráveis (1862), de Victor Hugo; O judeu errante (1844), de Eugène Sue, dentre outras, o que pode questionar se o nível dessa produção em massa pode ser visto apenas como literatura mediana. A esse respeito, o crítico Luiz Roncari afirma:

Foi a difusão do gosto e interesse pelo romance, numa camada receptiva que se ampliava, principalmente junto ao público feminino das famílias das capitais, que levou muitos a se dedicarem ao gênero. Ao longo das décadas de 30 e 40 do século XIX, foram vários os poetas e intelectuais que experimentaram o trabalho com a prosa, a novela curta e o romance, ainda mais quando os jornais passaram a publicar, nos seus rodapés, os folhetins. (RONCARI, 1995, p. 487)

A literatura como produto cultural iniciado pelos folhetins ainda persiste atualmente, visto que, influenciados pelos folhetins, best sellers ainda movimentam a cultura de massa percebida na literatura, sem contar a influência que esta produziu no cinema em série, nas radionovelas e, subsequentemente, nas telenovelas e outras produções televisivas, como no caso de séries e minisséries. Pois, bebendo da mesma fonte, muitas emissoras de rádio, no final dos anos de 1930, dramatizaram radionovelas para ganhar audiência, o que posteriormente influenciou a produção de novelas e seriados televisivos. 
Atualmente, as premissas, tanto estruturais quanto conteudistas que rodeavam e rodeiam ainda o gênero romance e, principalmente, o romancefolhetim - por ser o produto comercializado do gênero romance -, são encontradas em produtos culturais transmitidos por meio da TV, como é o caso de novelas, séries e minisséries.

Isto posto, dado seus objetivos mercadológicos, o romance-folhetim pode ser considerado como porta para uma literatura dentro da indústria cultural e, por conseguinte, congruente com a cultura de massa.

\section{CONSIDERAÇÕES FINAIS}

A partir das reflexões compreendidas, é visível a percepção a respeito da indústria cultural e seu viés mercadológico. Segundo os autores supracitados, para que se cumpra seu objetivo de lucratividade, há, por meio de uma ideologia consumista, a padronização de gosto realizada pela publicidade, organizada pelos meios de comunicação e preparada para um consumidor que busca ser entretido.

Por intermédio dos meios de comunicação e interativos, a indústria cultural se tornou, então, a principal movimentação no que se refere à arte no capitalismo moderno. Como parte da indústria cultural, há a literatura, a qual adentrou nesse processo mediante os folhetins, que eram intimamente ligados à imprensa, como também influenciou outras a ir na mesma direção, ao almejar lucro a partir da venda de suas obras.

Porém, é válido refletir que mesmo tendo como objetivo primordial a lucratividade, os folhetins e sua estreita ligação com o capitalismo, ajudaram a fomentar uma cultura de produções ficcionais, visto que, pelo viés literário, existiram grandes produções, veiculadas a partir da estrutura de folhetins, que mais tarde seriam incorporadas ao cânone. 


\section{REFERÊNCIAS}

ADORNO, Theodor; HORKHEIMER, Max. Dialektik der Aufklärung: Philosophische Fragmente. Frankfurt am Main: S. Fischer Verlag, 1944.

ADORNO, Theodor W; HORKHEIMER, Max. Dialética do esclarecimento. Trad. de Guido Antônio de Almeida. Rio de Janeiro: Zahar, 1985.

BOURDIEU, Pierre. O mercado de bens simbólicos. In: A Economia das Trocas Simbólicas. Trad. Sergio Miceli. $7^{\text {a }}$ Ed. São Paulo: Perspectiva, 2013.

CARDOSO, Nerione N. Jr. Hannah Arendt e o declínio da esfera pública. Brasília: Senado Federal, Subsecretaria de edições técnicas, 2005.

FREITAG, Bárbara. A teoria crítica ontem e hoje. São Paulo: Editora Brasiliense, 2004.

JACKS, Nilda. Mídia nativa: indústria cultural e cultura regional. Porto Alegre: Ed. Universidade/UFRGS, 1998.

KELLNER, D. Cultura da mídia e triunfo do espetáculo. In: MORAES, D. de (Org.). Sociedade midiatizada. Rio de Janeiro: Mauad, 2006, p. 119-147.

MEYER M. Folhetim, uma história. Rio de Janeiro: Companhia das Letras, 1996.

MORIN, E. Cultura de massas no século XX: neurose. 9. ed. Rio de Janeiro: Forense Universitária, 1997.

PUTERMAN, Paulo. Indústria Cultural: A Agonia de um Conceito. São Paulo: Editora Perspectiva, 1994.

RONCARI, Luiz. Literatura brasileira: Dos primeiros cronistas aos últimos românticos. São Paulo: EDUSP, 1995.

ZUIN, A. Á. S. Sobre a atualidade do conceito de indústria cultural. Cadernos Cedes, Campinas, ano XXI, n. 54, p. 9-18, agosto, 2001.

Nota do editor:

Artigo submetido para avaliação em: 04 de março de 2021

Aprovado em sistema duplo cego em: 11 de agosto de 2021 